\title{
A Study of English Proficiency Test among the First Year University Students
}

\author{
Ignasia Yuyun, Meyling, Naftalia Laksana \& Demus Abednego \\ ignasia_y@ukrida.ac.id, meyling.2014ude007@civitas.ukrida.ac.id \\ naftalia.2014ude011@civitas.ukrida.ac.id, demus.2014ude021@civitas.ukrida.ac.id \\ Universitas Kristen Krida Wacana (UKRIDA), Jakarta, Indonesia
}

\begin{abstract}
The study aims at analyzing the English skills in an English Proficiency Test (EPT) shown by students at tertiary level or university students, particularly the first year university students (freshmen). The study centers around the students' English skills represented in English Proficiency Test, which are then related to the students' common problems investigated in this study. The three sections in English Proficiency Test analyzed in this study including listening, structure and written expressions, and reading. This study revealed reading skill was the major problems faced by the first year of university students, particularly, in reviewing overall reading text. To solve this problem, the cognitive strategies, particularly the top-down reading strategies are suggested to anticipate the author's purpose, preview the text, think about what one already knows about the topic, skim for main points, etc. An effective reading strategies training which is more focused and explicit should be regularly practiced and enhanced since it can significantly boost reading proficiency and language acquisition.
\end{abstract}

Keywords: English Proficiency Test, university student

\section{Introduction}

In recent years, an increasing use of English as International Language (EIL) has been significantly proved in many fields around the world. This is proved by the use of English standardized testing employed in companies and institutions. They employ English Proficiency (TOEFL and IELTS) as one of the requirements in the recruitment process, such as scholarship programs. Particularly, in Indonesian educational institutions, a lot of educational institutions have been implementing TOEFL (Test of English as a Foreign Language) to measure the English-language ability of people who do not speak English as their first language and who plan to study at colleges and universities, either as undergraduate or graduate students (Phillips, 2003: xiii). Additionally, institutions such as government agencies, business, or scholarship programs may require this test
(Phillips, 2003: xiii). English language proficiency is utilized as a scale to measure the degree of an individual's relation in the fields of economy, business, politics, society, and education (Nallaya, 2012, cited in Bekdas, 2015: 14).

Like other developing countries, Indonesia is profoundly controlled by international business for its economic growth, English is deemed to be a prerequisite tool for success in any aspects of life. Both the government and the community in general recognize that a high level of English language ability among the workforce is essential (Hsu, 2010: 13). In the last few decades, there has been a growing concern for national standards of educational achievement in a competitive global economy. This concern has been reflected in tertiary institutions, the use of English Proficiency Test for the graduation requirement is then taken into account. To be 
in line with the market demand, the universities have been ensuring higher standards of English proficiency among students graduating from Indonesian tertiary institutions.

To respond global challenge, universities prepare their graduates with English Proficiency Test. The test result is expected to demonstrate students' English ability equals the Common European Framework of Reference for Languages (CEFR) (B1) level or above. English Proficiency Tests refer to tests that are designed to measure people's ability in a language. Major proficiency tests to fulfill the assessment purpose in this study are the General English Proficiency Test (GEPT), the Test of English for International Communication (TOEIC), the Test of English as a Foreign Language (TOEFL), the International English Language Testing System (IELTS), and the Cambridge ESOL Exams. All these proficiency tests, except for TOEIC, have a mixture of receptive and productive components: listening, reading, speaking and writing (Hsu, 2010: 15-16)

Moreover, as academic institutions, universities have been adopting Test of English as a Foreign Language (TOEFL) which is developed by Educational Testing Service. The TOEFL test gives students the opportunity to prove they can communicate ideas effectively by stimulating university classroom and student life communication. Besides, the TOEFL test measures how well students use English, not just their knowledge of the language. Because it is a valid and reliable test with unbiased, objective scoring, the TOEFL test confirms that a student has the English language skills necessary to succeed in an academic setting. That is why it is the most highly regarded and widely accepted test in the world.

Moreover, in this study, the English Proficiency Test is adopted from the ITP TOEFL which is simplified. It has three sections including listening comprehension, structure and written expression, and reading comprehension. Summarized from Preparation Course for the TOEFL Test (Phillips, 2003: xv). Firstly, listening comprehension is to demonstrate examinee's ability to understand spoken English, examinees must listen to various types of passages on a recording and respond to multiple choice questions about the passages (Phillips, 2003: xv). In this section, there are twenty-seven skills covered in three parts of Listening Comprehension section of the TOEFL test. The first part consists of thirty short conversations, the second part consists of two long conversations, and the third part consists of three talks. Secondly, Structure and Written Expression is to demonstrate examinee's ability to recognize grammatically correct English, examinees must either choose the correct way to complete sentences or find errors in sentences (Phillips, 2003: xv). In this section, there are sixty skills covered in two parts of Structure and Written Expression section of the TOEFL test. The first part consists of fifteen sentences in which part of the sentence has been replaced with a blank, the second part consists of twenty-five sentences in which four words or groups of words have been underlined. Here, the examinees are required to choose the incorrect parts. Lastly, the reading comprehension is to demonstrate examinee's ability to written English, examinees must answer multiple choice questions about the ideas and the meanings of words in reading passages (Phillips, 2003: $\mathrm{xv}$ ). In this section, there are thirteen skills covered in reading comprehension section of the TOEFL test. This part consists of questions about the ideas of the passage, directly answered questions, indirectly answered questions, vocabulary questions, and overall review questions.

Dealing with the previous study on the English Proficiency Test, particularly the TOEFL, Yuyun (2012: 34-35) delineated the Implied Detail Questions in reading comprehension are the most difficult question in reading faced by the first year university students in English Proficiency Test. In other words, the most common problem faced by the first year of university students is in finding information which is not directly stated in reading text. Meanwhile, the easiest question is Where Questions. In this case, the first year of university students do not have any difficulty 
in finding the explicit information from the reading texts.

In the context of second language (L2) acquisition, there are some factors affecting L2 learning including personal and general factor (Ellis, 1985: 124). The former are to be seen as a reflection of the latter. How the learner respond to the group dynamic of the learning situation or to the teacher and course materials, or how he selects study techniques are determined by age, aptitude, cognitive style, motivation, and personality. However, those general factors that are open to modification can also be influenced by a successful personal learning style. Personal and general factors have a joint effect on L2 proficiency (Ellis, 1985: 124). Nergis (2013: 1) highlighted some possible factors affecting the student's reading comprehension in a group of homogenous first language (L1). The study revealed the background of learners, depth of vocabulary knowledge was not a strong predictor of academic reading comprehension for English for Academic Purposes (EAP) students. However, it was found that syntactic awareness was a significant predictor of academic reading comprehension in second language (L2) and of the investigated variables, meta- cognitive reading strategies have much to contribute to academic reading comprehension (Nergis, 2013: 1). This findings are in line with Prichard's study revealing factors influencing reading proficiency include one's background knowledge, text structure, syntax, passive vocabulary, etc. (Prichard, 2014: 115).

Over the past four decades, researchers have identified a number of cognitive, affective, and sociocultural factors as significantly contributing to this variation in second language acquisition (SLA) (Brown, 2000, cited in Nisbet, Tindall, \& Beach, 2005: $100)$. From this body of research, language learning strategies (LLSs) consistently have emerged as a particularly significant variable. LLSs are defined as "specific actions taken by the learner to make learning faster, more enjoyable, more self-directed, more effective, and more transferable to new situations" (Oxford, 1990: 8). Stated another way, learning strategies are "measures that students can take to promote their own learning success" (Franklin, Hodge, \& Sasscer, 1997, cited in Nisbet, Tindall, and Beach, 2005: 100). Through LLSs do make learning easier in some senses, their purpose is much more significant: strategies make learning deeper, more productive, and more lasting (Cohen \& Macaro, 2007; Holschuh \& Altman, 2008; Winne \& Perry, 2000, cited in Oxford, 2011: 13).

Prichard (2014: 115) also revealed that cognitive and metacognitive strategy use is also influential. Cognitive strategies aid in constructing meaning from the text. They are often divided into bottom-up and top-down strategies, both of which are important. Bottom-up strategies include focusing on the meaning of each word and reading sentences in a linear fashion to construct the meaning of the text. Top-down reading means thinking about one's purpose, previewing the text, thinking about what one already knows about the topic, skimming for main points, etc. Metacognitive strategies are used to monitor the cognitive strategies; in other words the reader checks and evaluates his/her comprehension based on his/her objectives and revises one's strategies based on this.

Based on those perspectives above, this study is intended to investigate the English Proficiency Test results particularly major problems faced by university graduates. Thus, this study employed test analysis to analyze the English skills (listening, structure and written expression, and reading) in order to get intended research findings and possible learning strategies to cope with the identified lowest English skill.

\section{Method}

The subjects of this study were thirty university students in the first year (freshmen) in a private university in Jakarta. This initial data, the EPT pre-test, were collected to find the lowest skill in English Proficiency Test. The additional data were done from the EPT posttest from participants who joined the 10-hours training on the lowest skill. Moreover, the data collection was done through a test analysis based on the standardized TOEFL scoring and recapitulated in a cross-tabulation. The data 
analysis was conducted as follows: analysing test questions carefully number per number, analysing examinees' answers carefully number per number and identifying the skills for each number, recapitulating the results of data of each examinee based on the skills available on TOEFL to analyze the major problems found on the English Proficiency Test, interpreting the result of analysis is based on the percentage number of the major problems found on the English Proficiency Test and finally, comparing the result of analysis between the TOEFL Prediction Test (the first data) and the TOEFL Post Test (the second data) by repeating the first 3 processes.

\section{Findings and Discussions}

The data was analyzed quantitatively. There were three skills that would be considered in measuring the English Proficiency Test (EPT) including listening, structure and written expression, and reading. Based on the pre-test result, most students found that reading skill is the most difficult one. Most students consider reading section as the most difficult section in the English Proficiency Test since reading comprehension involves several processes working together (Alderson, 2000; Bernhardt, 1991; Grabe \& Stoller, 2014, cited in Prichard, 2014: 115).

To deal with the reading section in the English Proficiency Test, the students are expected to apply cognitive and metacognitive strategies. In this extent, Prichard (2014: 115) suggested cognitive strategies aid in constructing meaning from the text and metacognitive strategies are used to monitor the cognitive strategies. It means the students check and evaluate their comprehension based on their objectives and revise one's strategies based on this. The cognitive strategies are divided into bottom-up and top-down strategies, both of which are important. Bottom-up strategies include focusing on the meaning of each word and reading sentences in a linear fashion to construct the meaning of the text. Top-down reading means thinking about one's purpose, previewing the text, thinking about what one already knows about the topic, skimming for main points, etc.

As seen in Chart 1, listening skill has the highest percentage (36\%) among student's correct answers. Then, it is followed by structure and written expression (28\%) and reading skill (24\%). It means that reading skill is the lowest skill in English Proficiency Test faced by the first year university students. This fact is surprising since the reading skill as a part of integrated skills in TOEFL plays the important role. The university students are expected to read and understand information from textbooks and other academic materials written in English (Yuyun, 2012: 33). In the tertiary level, reading comprehension abilities allow students to access knowledge, understand and elaborate concepts always integrating information from lectures and reference books' content (Tavares, 2002).

The Percentage Average of Correct Answers

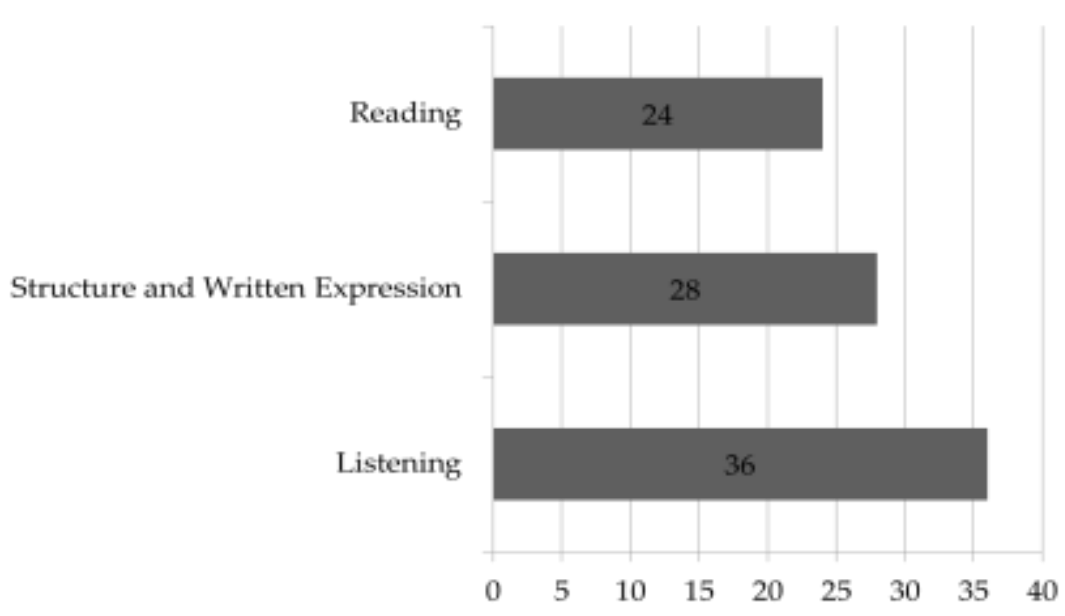

Chart 1. Comparative Percentages of English Skills 
In particular, reading skill covers five (5) skills including questions about ideas of the passage, directly answered questions, indirectly answered questions, vocabulary, and overall review. As seen in Chart 2, among those five skills, directly answered questions has the highest percentage (40\%). Then, it is followed by vocabulary (28\%), indirectly answered questions $(14 \%)$, questions about ideas of the passage $(10 \%)$, and overall review $(8 \%)$.

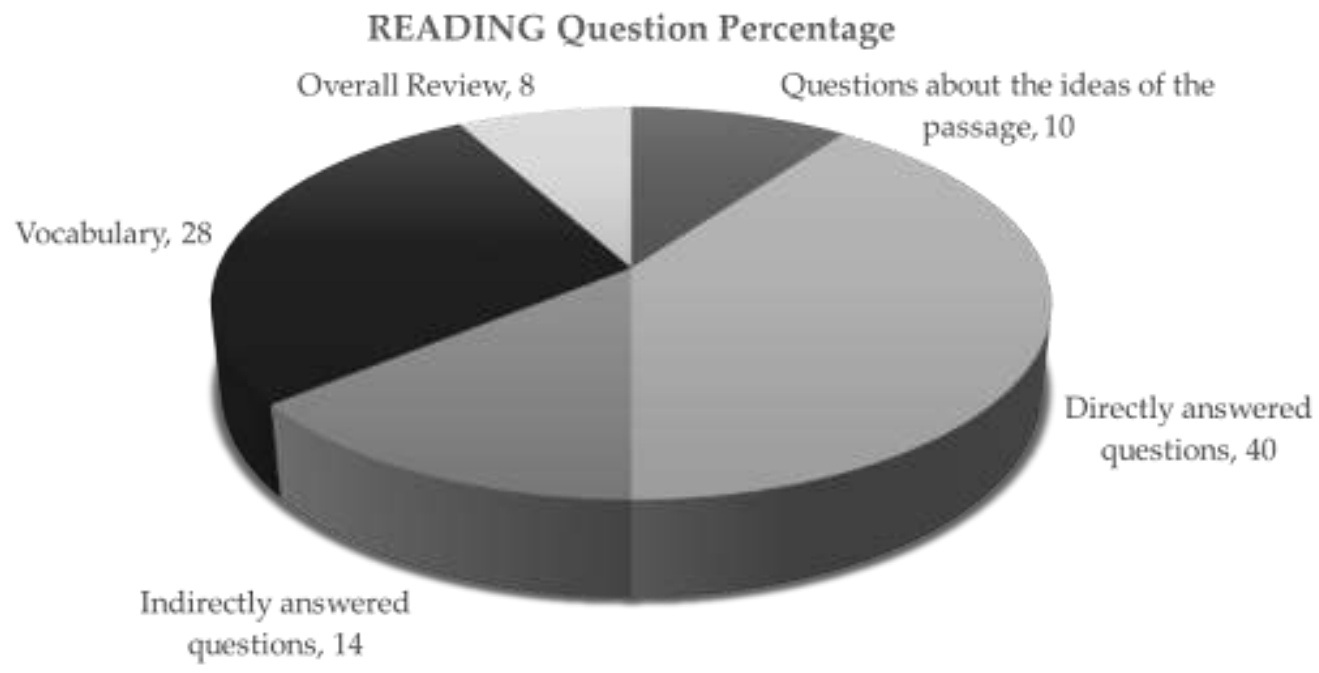

Chart 2. Comparative Percentages of Reading Questions

Dealing with reading skill questions in EPT pre-test, the students found that overall review is the most challenging question. This fact is shown in Chart 3. The overall review has the lowest percentage (22\%). Meanwhile, the other questions are around $33-58 \%$. This indicates that students' lowest reading skill is reviewing the reading text generally. This skill includes determining where specific information is found and determining the tone, purpose, or course (Phillips, 2003: 306-309). Often in the reading comprehension section of the TOEFL test, the last question (or two) for a particular reading passage is an overall question, one that asks about the passage as a whole rather than one small detail. The overall review questions are generally not main idea questions; instead, they ask about some other aspect of the passage as a whole. To cope with this problem, the students are expected to use cognitive strategies, particularly, the top-down reading. In this case, the students anticipate the author's purpose, preview the text, think about what one already knows about the topic, skim for main points, etc. (Prichard, 2014: 115). 


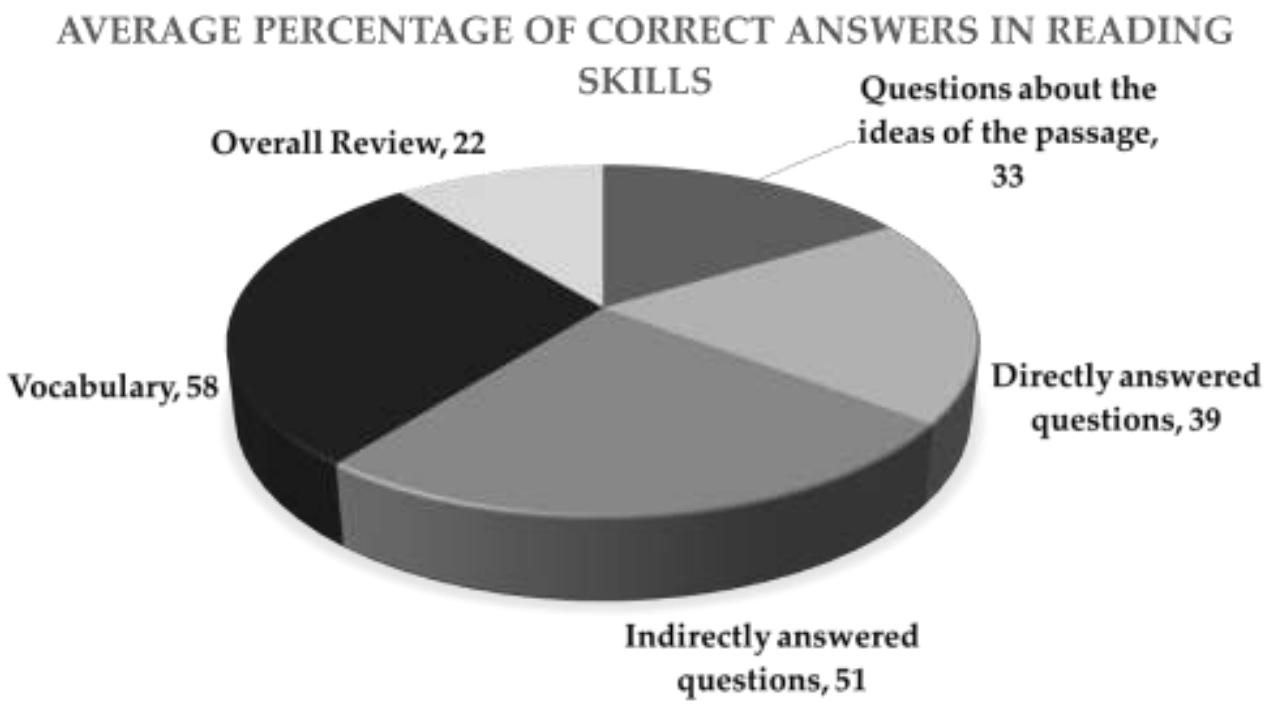

Chart 3. Comparative Percentages of Correct Answers in Reading (Pre-Test)

Moreover, it surprisingly reveals that the EPT post-test shows the consistent result. As shown in Chart 4, the overall review has the lowest percentage (33\%) and the other skills are around 59\%-68\%. This implies that the first year university students are still struggling with reviewing the passage generally. Again, the cognitive strategies, particularly, the top-down reading is highly suggested to cope with this reading problem.

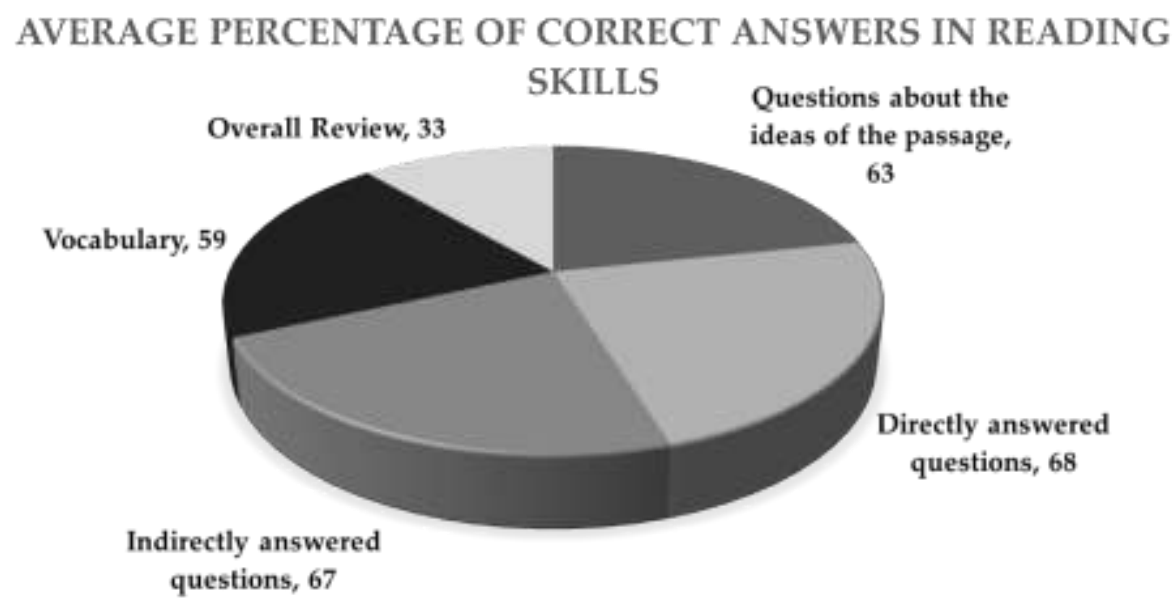

Chart 4. Comparative percentages of Average Correct Answers in Reading (Post-Test)

After the 10-hours training, the students have improved their reading skills as seen in Chart 5. This strategy training helps students improve their reading comprehension. The skill in dealing with the ideas of the passage has the highest percentage (48\%) compared to other skills (1-43\%). This reveals that the skill in dealing with the ideas of the passage is the most improved skill. Meanwhile, the vocabulary skill is the least improved skill. This fact is in line with Yuyun (2012: 35) revealing that vocabulary skill is one of the lowest skill in reading comprehension among the first year university students. Some possible vocabulary coping strategies (e.g. inferring meaning, ignoring unknown words, 
and dictionary use) are suggested to encourage students to use a dictionary only a limited number of times on their first reading, which encourages them to be more strategic in their dictionary use (Prichard, 2014: 120).

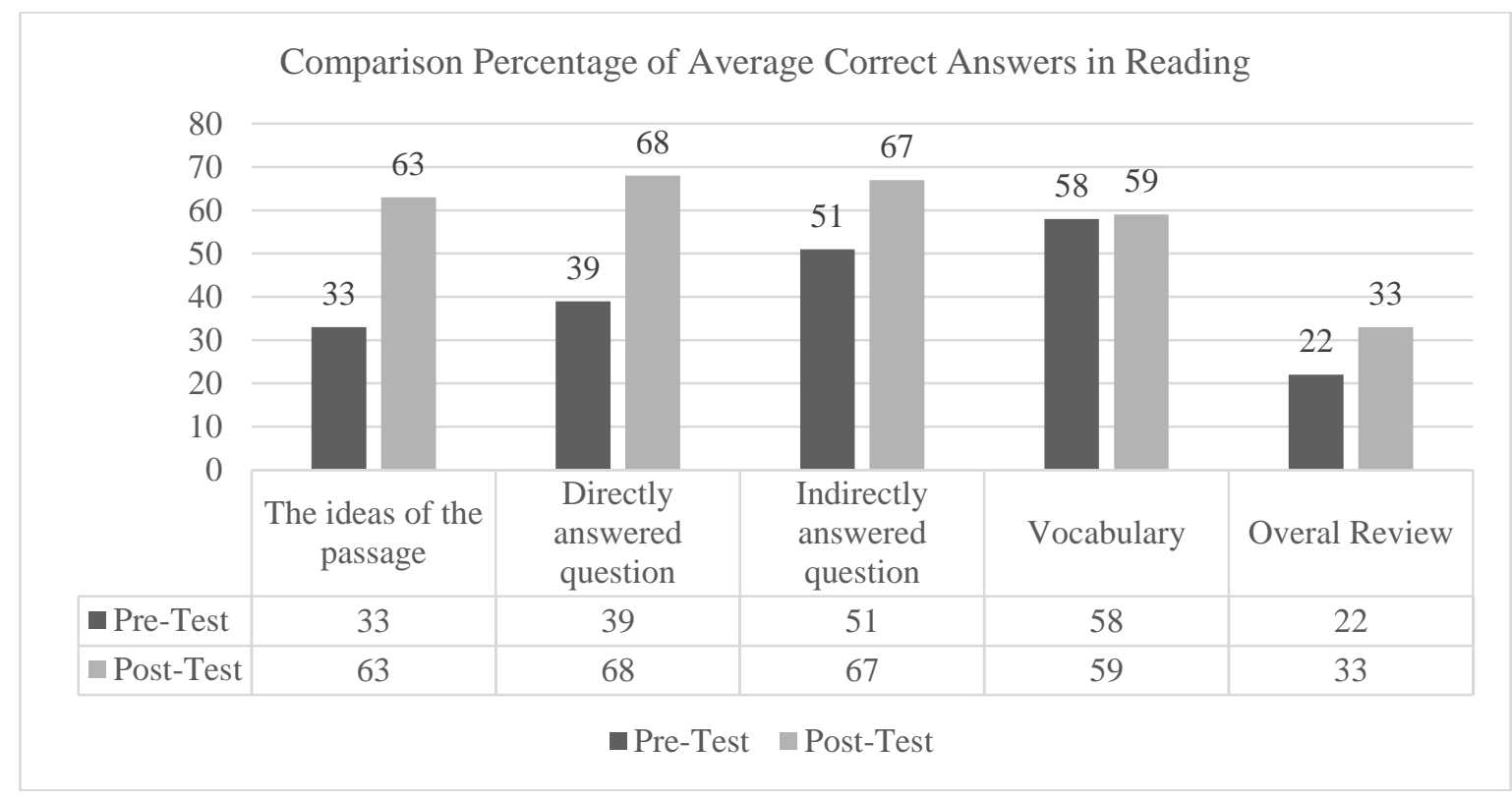

Chart 5. Comparative percentages of Average Correct Answers in Reading (Pre-Test and Post-Test)

The strategy training provides the taskbased instruction inducing students to read more strategically. Consequently, they have more intrinsic motivation or the need to read strategically. More explicit and focused strategy training may be necessary to get the significant result. Notably, effective reading strategy use may be a cause and an effect of proficiency.

\section{Conclusion}

Based on the main findings above, this study concludes that the major problem in English Proficiency Test (EPT) faced by the first year of university students is reading skill. Particularly, in reviewing overall text reading. To cope with this problem, the cognitive strategies, particularly the top-down reading strategies are suggested to anticipate the author's purpose, preview the text, think about what one already knows about the topic, skim for main points, etc. An effective reading strategies training which is more focused and explicit should be regularly practiced and enhanced since it can significantly boost reading proficiency and language acquisition.

\section{References}

Bekdas, Buket. Identifying Factors Related To Students' English Proficiency Levels Through A Segmentation Method. May 2015: Web. 2 February 2018. <http://www.thesis.bilkent.edu.tr/0006 872.pdf>

Educational Testing Service (ETS). The Official Guide to the TOEFL Test. New York: McGraw-Hill, 2009.

Ellis, Rod. Understanding Second Language Acquisition. Oxford: Oxford University Press, 1985.

Hsu, Hui-Fen. "The Impact of Implementing English Proficiency Tests as a Graduation Requirement at Taiwanese Universities of Technology." Educational Studies. November 2010: Web. 2 June 2017. <http://etheses.whiterose.ac.uk/576/>

Nergis, Ayşegül. "Exploring the Factors That Affect Reading Comprehension of EAP Learners." Journal of English for Academic Purposes. 2013: pp.1-9. Web. 1 December 
2017.

<https://www.researchgate.net/publicat ion/257603807_Exploring_the_factors_th at_affect_reading_comprehension_of_EAP _learners>

Nisbet, Deanna L, Evie R Tindall, and Universitx Virginia Beach. "Language Learning Strategies and EnglishProficiency of Chinese University Students." Foreign Language Annals. 2005: pp.100-107. Web. 1 July 2017. < http://web.pdx.edu/ fischerw/courses/ advanced/methods_docs/pdf_doc/wbf_c ollection/0351_0400/0399abs_FLA_2005 _Strategies_China_Nisbet.pdf>

Oxford, Rebecca, L. Language Learning Strategies: What Every Teacher Should Know. New York: Newbury House. 1990.

Oxford, Rebecca, L. Teaching and Researching Language Learning Strategies. New York: Routledge, 2011.

Papageorgiou, Spiros et al. The Association Between TOEFL iBT $₫$ Test Scores and the Common European Framework of Reference (CEFR) Levels. Ed. James Carlson. New Jersey: Educational Testing Service, 2015. Web. 2 Jul 2017.

$<$ https://www.ets.org/Media/Research/pdf/ RM-15-06.pdf >

Phillips, Deborah. Longman Introductory Course for the TOEFL Test. New York: Pearson Education, Inc., 2003.

Prichard, Caleb. Reading Strategy Use of Lowand High-Proficiency Learners and the Effect of Reading Instruction. 2014: pp.115-122. Web. 10 February 2017. <http://ousar.lib.okayamau.ac.jp/files/p ublic/5/53178/2016052812143234680 /bhe_010_115_122.pdf>

Tavares, Ana Paula Cabral \& Jose. "Reading and Writing Skills in Higher Education: Lecturers' Opinions and Perceptions." The European Conference on Educational Research. 2002: Web. 10 February 2017. <http://www.leeds.ac.uk/educol/docum ents/00002179.htm>
Yuyun, Ignasia. "A Study of Reading Skills in An English Proficiency Test." Ninth Conference on English Studies (CONEST 9). Ed. Yanti. Jakarta: Center for Studies on Language and Culture - Atma Jaya Catholic University of Indonesia, 2012. pp.33-25. Print. 